\title{
Challenges and priorities for modelling livestock health and pathogens in the context of climate change
}

Şeyda Özkan ${ }^{\mathrm{a}, 1}$, Andrea Vitali ${ }^{\mathrm{b}}$, Nicola Lacetera ${ }^{\mathrm{b}}$, Barbara Amon $^{\mathrm{c}}$, André Bannink ${ }^{\mathrm{d}}$, Dave J. Bartley $^{\mathrm{e}}$, Isabel Blanco-Penedo ${ }^{\mathrm{f}}$, Yvette de Haas ${ }^{\mathrm{d}}$, Isabelle Dufrasne ${ }^{\mathrm{g}}$, John Elliott ${ }^{\mathrm{h}}$, Vera Eory $^{\mathrm{i}}$, Naomi J. Fox ${ }^{\mathrm{j}}$, Phil C. Garnsworthy ${ }^{\mathrm{k}}$, Nicolas Gengler ${ }^{1}$, Hedi Hammami ${ }^{1}$, Ilias Kyriazakis $^{\mathrm{m}}$, David Leclère ${ }^{\mathrm{n}}$, Françoise Lessire ${ }^{\mathrm{g}}$, Michael Macleod $^{\mathrm{i}}$, Timothy P. Robinson ${ }^{\mathrm{o}}$, Alejandro Ruete ${ }^{\mathrm{p}}$, Daniel L. Sandars ${ }^{\mathrm{q}}$, Shailesh Shrestha ${ }^{\mathrm{i}}$, Alistair W. Stott ${ }^{\mathrm{i}}$, Stanislaw Twardy $^{\mathrm{r}}$, Marie-Laure Vanrobays ${ }^{1}$, Bouda Vosough Ahmadi, ${ }^{\mathrm{i}, 2}$, Isabelle Weindl ${ }^{\mathrm{c}, \mathrm{s}}$, Nick Wheelhouse $^{\mathrm{e}}$, Adrian G. Williams ${ }^{\mathrm{q}}$, Hefin W. Williams ${ }^{\mathrm{t}}$, Anthony J. Wilson ${ }^{\mathrm{u}}$, Søren $\emptyset_{\text {stergaard }^{\mathrm{v}} \text { and Richard P. Kipling }}^{\mathrm{s}, *}$

${ }^{a}$ Department of Animal and Aquacultural Sciences, Faculty of Veterinary Medicine and Biosciences, Norwegian University of Life Sciences (NMBU), Post box 5003, Ås 1430, Norway

${ }^{b}$ University of Tuscia, Department of Agriculture and Forestry Science (DAFNE), Via San Camillo De Lellis, snc, Viterbo 01100, Italy

${ }^{c}$ Leibniz Institute for Agricultural Engineering Potsdam-Bornim (ATB), Max-Eyth-Allee 100, Potsdam 14469, Germany

${ }^{\mathrm{d}}$ Wageningen UR Livestock Research, P.O. Box 338, Wageningen $6700 \mathrm{AH}$, The Netherlands

${ }^{\mathrm{e}}$ Moredun Research Institute, Pentlands Science Park, Bush Loan, Penicuik EH26 0PZ, UK ${ }^{\mathrm{f}}$ Animal Welfare Subprogram, IRTA, Veinat de Sies s/n, Monells, Girona 17121, Spain

${ }^{\mathrm{g}}$ Nutrition Unit, Animal Production Department, Veterinary Faculty, University of Liège, Boulevard de Colonster 20, Bât. B43, Liège 4000, Belgium

${ }^{\mathrm{h}}$ ADAS UK Ltd, 4205 Park Approach, Thorpe Park, Leeds LS15 8GB, UK

iScotland's Rural College (SRUC), Peter Wilson Building, Kings Buildings, West Mains Road, Edinburgh EH9 3JG, UK

${ }^{\mathrm{j} S}$ Scotland's Rural College (SRUC), Animal and Veterinary Sciences, Roslin Institute Building, Easter Bush, Midlothian EH25 9RG, UK

\footnotetext{
${ }^{1}$ Permanent address: Department of Animal Health Economics and Management, Faculty of Veterinary Medicine, Mehmet Akif Ersoy University, Burdur 15030, Turkey

${ }^{2}$ Present address: European Commission, Joint Research Centre, Institute for Prospective Technological Studies, Spain
}

(C) 2016. This manuscript version is made available under the CC-BY-NC-ND 4.0 license: http://creativecommons.org/licenses/by-nc-nd/4.0/ 
${ }^{\mathrm{k}}$ University of Nottingham, School of Biosciences, Sutton Bonington Campus, Loughborough LE12 5RD, UK

${ }^{1}$ Agriculture, Bio-engineering and Chemistry Department, Gembloux Agro-Bio Tech, University of Liège, Passage des Déportés, 2, Gembloux B-5030, Belgium

${ }^{\mathrm{m}}$ School of Agriculture, Food and Rural Development, Newcastle University, King's Road, Newcastle upon Tyne NE1 7RU, UK

${ }^{\mathrm{n}}$ Ecosystems Services and Management program (ESM), International Institute for Applied Systems Analysis (IIASA), Schlossplatz 1, Laxenburg A-2361, Austria

${ }^{\circ}$ Livestock Systems and Environment, International Livestock Research Institute, P.O. Box 30709, Nairobi 00100, Kenya

${ }^{\mathrm{p}}$ Department of Ecology, Swedish University of Agricultural Sciences. Ullsvägen 16, Uppsala 75007, Sweden

${ }^{\mathrm{q}}$ School of Energy, Environment and Agrifood, Cranfield University, Bedford, MK43 0AL, UK

${ }^{\mathrm{r}}$ Institute of Technology and Life Sciences at Falenty (P122) Malopolska Research Centre in Krakow 31-450 Krakow, ul. Ulanow 21B, Poland

${ }^{\text {s} P o t s d a m ~ I n s t i t u t e ~ f o r ~ C l i m a t e ~ I m p a c t ~ R e s e a r c h ~(P I K), ~ P O ~ B o x ~} 6012$ 03, 14412 Potsdam, Germany

tInstitute of Biological, Environmental and Rural Sciences (IBERS), Aberystwyth University, $1^{\text {st }}$ Floor, Stapledon Building, Plas Gogerddan, Aberystwyth, Ceredigion SY23 3EE, UK

uThe Pirbright Institute, Pirbright, Woking, Surrey GU24 0NF, UK

${ }^{\vee}$ Department of Animal Science, Aarhus University, Tjele 8830, Denmark

* Corresponding author: Email: rpk@aber.ac.uk, Phone: +441970823160 


\section{ABSTRACT}

Climate change has the potential to impair livestock health, with consequences for animal welfare, productivity, greenhouse gas emissions, and human livelihoods and health. Modelling has an important role in assessing the impacts of climate change on livestock systems and the efficacy of potential adaptation strategies, to support decision making for more efficient, resilient and sustainable production. However, a coherent set of challenges and research priorities for modelling livestock health and pathogens under climate change has not previously been available. To identify such challenges and priorities, researchers from across Europe were engaged in a horizon-scanning study, involving workshop and questionnaire based exercises and focussed literature reviews. Eighteen key challenges were identified and grouped into six categories based on subject-specific and capacity building requirements. Across a number of challenges, the need for inventories relating model types to different applications (e.g. the pathogen species, region, scale of focus and purpose to which they can be applied) was identified, in order to identify gaps in capability in relation to the impacts of climate change on animal health. The need for collaboration and learning across disciplines was highlighted in several challenges, e.g. to better understand and model complex ecological interactions between pathogens, vectors, wildlife hosts and livestock in the context of climate change. Collaboration between socio-economic and biophysical disciplines was seen as important for better engagement with stakeholders and for improved modelling of the costs and benefits of poor livestock health. The need for more comprehensive validation of empirical relationships, for harmonising terminology and measurements, and for building capacity for under-researched nations, systems and health problems indicated the importance of joined up approaches across nations. The challenges and priorities identified can help focus the development of modelling capacity and future research structures in this vital field. Well-funded networks capable of managing the longterm development of shared resources are required in order to create a cohesive modelling community equipped to tackle the complex challenges of climate change.

Keywords: animal health; climate change; greenhouse gas emissions; pathogens; modelling 


\section{Funding sources}

This paper was supported by the FACCE-JPI knowledge hub Modelling European Agriculture with Climate Change for Food Security (MACSUR) and the Animal Health Network of the Global Research Alliance, with additional support from the Norwegian Research Council, SPW (Belgium), MSTI (Denmark), JÜLICH and BLE (Germany), MIPAAF (Italy), NCRD (Poland), INIA (Spain) and DEFRA, RESAS and BBSRC (UK), H2020 SUSFANS Grant Number 633692 (D. Leclère), ESEI UrbanZoo and CGIAR A4NH (T.P. Robinson). 


\section{INTRODUCTION}

Livestock agriculture is facing the complex and multi-faceted challenge of delivering efficient and sustainable production under climate change, while meeting growing demand for livestock products (Tilman and Clark, 2014). At the same time, the sector must reduce its estimated $14.5 \%$ contribution to global greenhouse gas (GHG) emissions (Gerber et al., 2013) and minimize other environmental impacts of production. Globally, it is estimated that livestock disease reduces productivity by $25 \%$ with the heaviest burden falling on the poor (Grace et al., 2015). Evidence is growing about the impacts of impaired health on product yield and quality (Bareille et al., 2003; Williams et al., 2013) and on GHG emissions intensity (Gerber et al., 2011; Kenyon et al., 2013; Özkan et al., 2015a), in addition to the costs in terms of livestock welfare and the risks to human health associated with zoonoses and emerging diseases (CDCP, 2015; Wilkinson et al., 2011). Tackling impaired health in livestock may therefore increase productivity while at the same time reducing the intensity of GHG emissions (Stott et al., 2012; Stott et al., 2010) and improving animal welfare. However, efforts to improve livestock health must take place in the context of interacting environmental and socio-economic changes, including climate change, ecological disruption, globalisation, and the intensification of livestock production (Perry et al 2011). These changes are expected to affect the emergence and spread of epidemic diseases (Perry et al., 2013), and the prevalence and severity of some endemic diseases (Fox et al., 2011).

Tackling animal health problems has been identified as a priority in recent research agendas (ATF, 2013; ATF, 2014; FACCE-JPI, 2012). However, in the context of the global trends described, the complexity of pathogen ecology and transmission, the direct impacts of climate change on animal health, and interactions between all these factors form highly complex systems which are challenging to understand or positively affect. Models, which can reveal unseen interactions, and enable the evaluation of management and policy choices in a 'risk free' virtual environment, are vital tools for exploring complex systems (Van Paassen et al., 2007). In order to contribute more effectively to efforts to tackle animal health problems in the context of climate change, modellers need to work across disciplines to build capacity and share best practice (Kipling et al., 2014). Inter-disciplinary efforts should be designed to support and strengthen work within the diverse fields involved in health and pathogen modelling, recognising the costs as well as the benefits of working across different areas of expertise (Siedlok and Hibbert, 2014). 
A wide range of approaches are applied to modelling livestock health and pathogens under climate change (Fig. 1). Within each of the modelling areas shown, approaches can be more empirical (based on statistical relationships between variables) or mechanistic/process-based (using mathematical equations to describe the mechanisms underlying statistical relationships) (Kipling et al., 2016a). The former can be developed quickly but rely on the quality of data within which the statistical relationship was observed, while the latter can be used to explore future changes in systems, including changes in statistical relationships that might arise, e.g. in novel climatic conditions. The modelling depicted can also be undertaken at a range of scales; e.g. pathogen spread and disease risk might be modelled at farm scale, (usually more mechanistic approaches) or at regional scales (usually more empirical approaches). Finally, modelling can be used to predict future changes in both infectious and non-infectious diseases, or to model the progress of current outbreaks in support of practical responses.

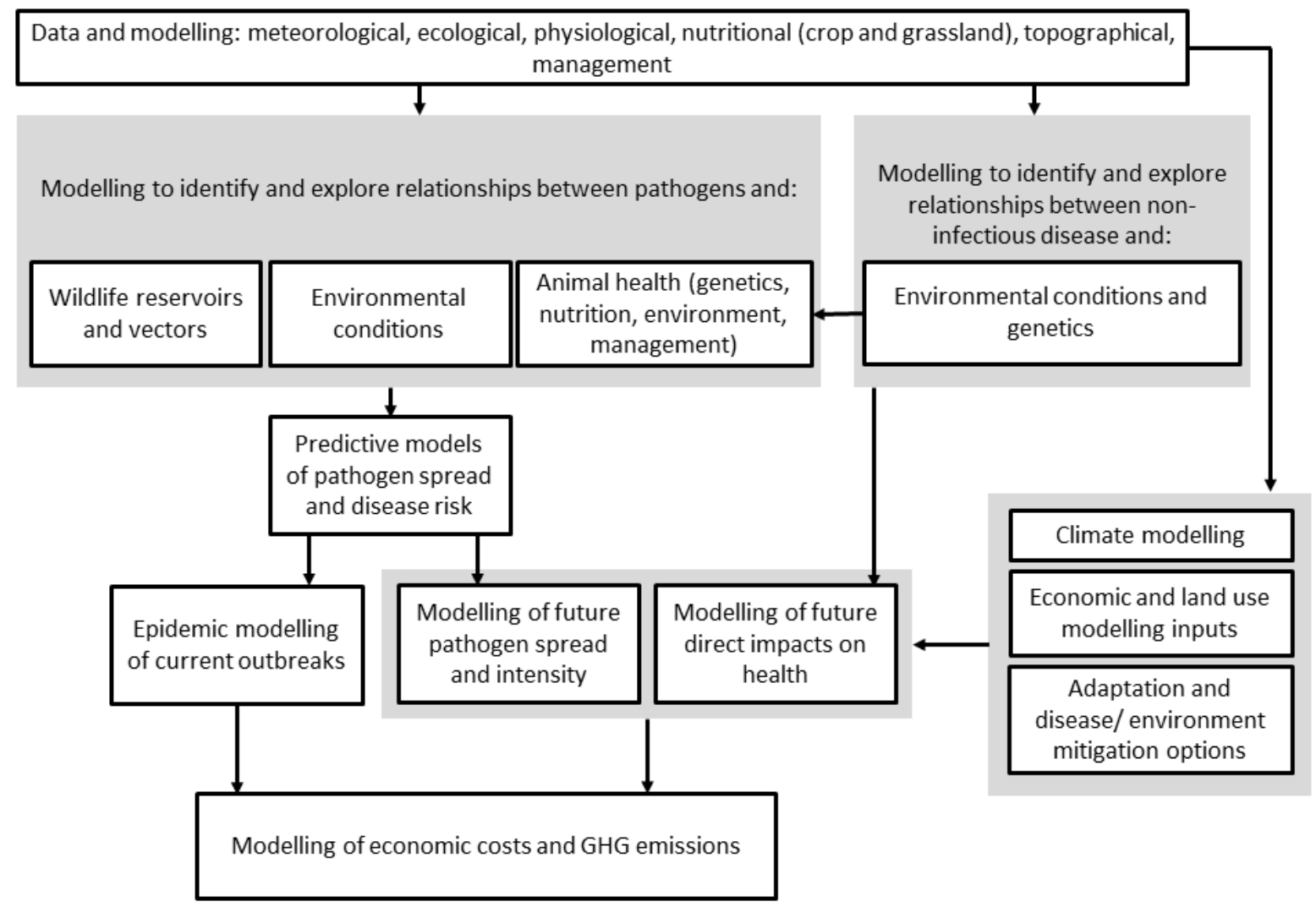

Fig. 1. Overview of livestock health and pathogen modelling, and interactions with other modelling disciplines. 
Although recent collaborative exercises and reviews have identified priorities for modelling in some key areas, such as the modelling of infectious livestock diseases (Brooks-Pollock et al., 2015) and disease distribution modelling (focused on the spatial spread of pathogens and vectors) (Purse and Golding, 2015) to the authors knowledge none have attempted to provide an overview of challenges and research priorities for livestock health and pathogen modelling across disciplines in the context of climate change. The aim of the current study is to present a framework of key challenges for modelling in this field, providing a clear focus and agenda for future research and funding, and acting to bring together modellers and experimental researchers in livestock health in Europe around a set of common objectives.

\section{MATERIALS AND METHODS}

The views of 34 modellers and experimental researchers from 21 institutes across 12 countries were garnered to gain an overview of the challenges facing the diverse research communities engaged in livestock health modelling. Experts were drawn from two major research networks: 1) the FACCE JPI (Agriculture, Food Security and Climate Change Joint Programming Initiative) knowledge hub MACSUR (Modelling European Agriculture with Climate Change for Food Security; www.macsur.eu) and 2) the GRA (Global Research Alliance) Animal Health and GHG Emissions Intensity Network (http://tinyurl.com/GRAhealth). A 'horizon scanning' approach (Pretty et al., 2010) was applied in a three stage process; a mapping process, a workshop and questionnaire, and a final synthesis following the methods of Kipling et al. (2016b) (in which full details of the process are described).

A map of the impacts of climate change on livestock health, and the mediation of these effects by management was created to provide an overview of the research area, and to inform later discussions (Fig. 2). The impacts of climate change on livestock health were defined as either direct or indirect. Direct impacts include behavioural and physiological effects that environmental change has on livestock (such as heat stress caused by increased temperature) while indirect impacts are those that alter other variables (such as pathogen spread) that in turn affect livestock. The map was used as a reference during workshop discussions, and accompanied the electronic questionnaire. 


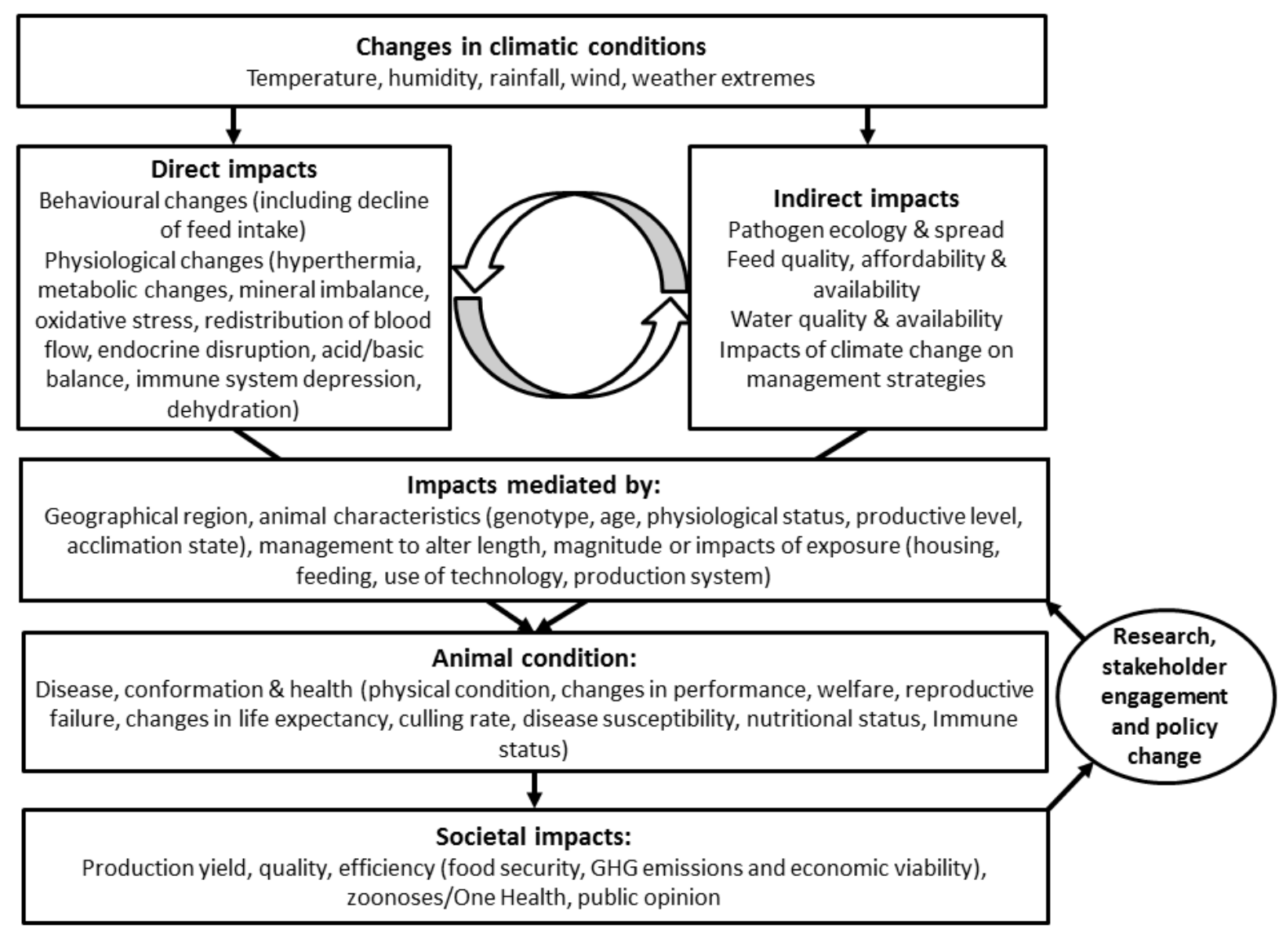

Fig. 2. The systems, processes and components relevant to modelling the impacts of climate change on livestock health and pathogens.

The workshop, involving 15 experts from across Europe, was held at the University of Reading (UK) on the $24^{\text {th }}$ June 2015. A questionnaire was then used to collect views from network partners unable to attend the event. Finally, contributing partners were asked to review the literature relating to the research challenges identified, in order to (i) explore any novel ideas generated by the workshop process; and (ii) to evaluate the challenges.

\section{RESULTS}

The identified challenges for modelling could be grouped into six themes, according to the aspects of modelling to which they related (Table 1). The challenges within each theme are presented in logical order and are not ranked, as they refer to different areas of modelling, and to both capacity building and topical challenges which should be worked on together. The description of each challenge is accompanied by a brief overview of the current state of modelling in that area, and a description of the research priorities highlighted by the experts. 
Table 1. Challenges to modelling and their relevance to different groups of models.

\begin{tabular}{|c|c|c|c|c|c|c|c|}
\hline \multirow[b]{2}{*}{ Group } & \multirow[b]{2}{*}{ Challenge } & \multirow[b]{2}{*}{ No. } & \multicolumn{5}{|c|}{ Modelling topic linked to each challenge } \\
\hline & & & $\begin{array}{l}\text { Direct climate } \\
\text { impacts }\end{array}$ & $\begin{array}{l}\text { Current } \\
\text { epidemics }\end{array}$ & $\begin{array}{l}\text { Future pathogen \& } \\
\text { vector intensity \& spread }\end{array}$ & $\begin{array}{l}\text { Greenhouse gas } \\
\text { (GHG) emissions }\end{array}$ & Economics \\
\hline \multirow{3}{*}{$\begin{array}{l}\text { Modelling impacts } \\
\text { on health }\end{array}$} & Impacts of climate on health & 1 & $\bullet$ & $\bullet$ & $\bullet$ & $\bullet$ & $\bullet$ \\
\hline & Nutrition \& health & 2 & $\bullet$ & & $\bullet$ & $\bullet$ & \\
\hline & Genetics \& health & 3 & & $\bullet$ & $\bullet$ & & \\
\hline \multirow{2}{*}{$\begin{array}{l}\text { Modelling pathogens } \\
\text { \& vectors }\end{array}$} & Pathogen, vector \& wildlife host ecology & 4 & $\bullet$ & $\bullet$ & $\bullet$ & & \\
\hline & Pathogen \& vector spread & 5 & $\bullet$ & & $\bullet$ & $\bullet$ & \\
\hline \multirow{2}{*}{$\begin{array}{l}\text { Modelling impacts } \\
\text { of poor health }\end{array}$} & Economic impacts of health on production & 6 & $\bullet$ & $\bullet$ & $\bullet$ & $\bullet$ & $\bullet$ \\
\hline & Impacts of health on GHG emissions & 7 & & $\bullet$ & $\bullet$ & $\bullet$ & $\bullet$ \\
\hline \multirow{3}{*}{$\begin{array}{l}\text { Modelling } \\
\text { interactions \& } \\
\text { management }\end{array}$} & Land use change \& health & 8 & $\bullet$ & $\bullet$ & $\bullet$ & $\bullet$ & $\bullet$ \\
\hline & $\begin{array}{l}\text { Interactions between health conditions, } \\
\text { pathogens \& interventions }\end{array}$ & 9 & $\bullet$ & $\bullet$ & $\bullet$ & $\bullet$ & $\bullet$ \\
\hline & Adaptation \& mitigation strategies & 10 & $\bullet$ & $\bullet$ & $\bullet$ & $\bullet$ & $\bullet$ \\
\hline \multirow{4}{*}{$\begin{array}{l}\text { Data \& } \\
\text { evaluation }\end{array}$} & Data quality & 11 & $\bullet$ & $\bullet$ & $\bullet$ & $\bullet$ & $\bullet$ \\
\hline & Data accessibility & 12 & $\bullet$ & $\bullet$ & $\bullet$ & $\bullet$ & $\bullet$ \\
\hline & Terminology \& measurements & 13 & $\bullet$ & $\bullet$ & $\bullet$ & $\bullet$ & $\bullet$ \\
\hline & Validation of empirical relationships & 14 & $\bullet$ & & & $\bullet$ & $\bullet$ \\
\hline \multirow{4}{*}{$\begin{array}{l}\text { Model scope \& } \\
\text { relevance }\end{array}$} & Variation in capacity between systems \& nations & 15 & $\bullet$ & $\bullet$ & $\bullet$ & $\bullet$ & $\bullet$ \\
\hline & Spatial \& temporal scales & 16 & $\bullet$ & $\bullet$ & $\bullet$ & $\bullet$ & $\bullet$ \\
\hline & Fit-for-purpose models & 17 & $\bullet$ & $\bullet$ & $\bullet$ & $\bullet$ & $\bullet$ \\
\hline & Stakeholder involvement & 18 & $\bullet$ & $\bullet$ & $\bullet$ & $\bullet$ & $\bullet$ \\
\hline
\end{tabular}

Note: Numbers refer to the order of challenges in the text 


\section{Modelling impacts on health}

\section{Impacts of climate on health}

Climate change is expected to increase the frequency and severity of extreme events, such as floods and heatwaves, as well as changing average conditions. In this context, a number of researchers have investigated the impacts of heat stress on dairy cow health (Collier and Gebremedhin, 2015; Vitali et al., 2015) and product quantity and quality (Bernabucci et al., 2014; Bertocchi et al., 2014; Hammami et al., 2013). Temperature Humidity Index (THI) values (Lacetera et al., 2013) and the milk production responses of cows to high temperatures (Carabaño et al., 2016) have been found to vary across environments and systems. Although these investigations have yielded empirical functions characterising the impacts of heat stress, these functions do not take into account the way that livestock characteristics such as breed, milk yield, or level of acclimation affect the occurrence of heat stress and impacts on production. The FACCE ERA-NET project OptiBarn (http://www.optibarn.atbpotsdam.de/en/optibarn.html) aims to address this weakness by developing a new indicator for heat stress that will include climatic and individual animal parameters. However, the range of variables affecting heat stress, and the impacts of climate change adaptation and mitigation strategies, cannot be incorporated into the empirical models described, and more mechanistic approaches are required (Kipling et al., 2016a). A dynamic mechanistic thermal balance model has been developed to estimate heat production and heat flows in cattle, using meteorological, dietary and physiological response data (Thompson et al., 2014). However, few modelling investigations focus on other potential direct impacts of climate change on livestock health (Fig. 1) and process-based modelling approaches have yet to be applied to include other aspects of the system (e.g. different levels of production intensity or coverage of different types of cattle production).

Climate driven changes in water availability are likely to affect options for adaptation to increased heat (McDowell et al., 1969) and pathogen related stresses (Silanikove, 2000). By altering the temporal and spatial distribution of water, climate change will also indirectly affect health through changes in the ecology and spread of some pathogens and vectors (Bolin et al., 2004; Jamison et al., 2015; Semenza, 2015). Many interactions between water and pathogens remain to be addressed in modelling, such as the effects of diminishing water availability on livestock-wildlife cross infection, the effects of summertime 
evapotranspiration on pathogen flow, and base flow contribution to pathogens in water sources (Dorner et al., 2006). Models also need to incorporate changes in pathogen concentrations as water levels decrease and grazing becomes limited. Interactions between agricultural sectors will be important to consider, given that the adaptive responses of arable farmers to climate change (such as increasing irrigation) are expected to increase pressure on water resources, as shown in Europe (Leclère et al., 2013). At present, few models characterise the potential effects of climate-related changes in grassland and crop management, or grazing behaviour, on livestock health and pathogens (Cornell, 2005; Fox et al., 2013). Similarly, few grassland models incorporate health-related changes in grazing management or livestock grazing behaviour in their predictions of sward productivity and quality (Baumont et al., 2004).

\section{Priorities}

To develop modelling capacity, an inventory of relationships between environmental conditions and livestock health issues is required, including information on how well each association is understood and on the seriousness of related health impacts. Data comparisons across regions and systems can generate greater understanding of climate change impacts on livestock health and pathogens (Challenge 15); setting up experimental systems in different regions as a basis for future modelling would therefore be an important step in developing knowledge. To understand how climate change may affect systems as a whole, grassland and livestock health modellers need to work together to review current modelling capacity and options for improvement in the characterisation of relationships between pathogen ecology and transmission, livestock health and grazing strategies. Livestock modellers also need to engage with crop and grassland modellers to develop a mutual understanding of the priorities for modelling grass and crop nutritional value (Soussana et al., 2013) and management in the context of climate change.

\section{Nutrition and health}

Vulnerability to pathogens and poor health can be affected by nutrition, while poor health can alter feeding behaviour, feed intake and nutrient utilisation (Vagenas et al., 2007). This in turn is likely to influence livestock production efficiency, and GHG emissions intensity (Challenges 6 and 7). Some nutritional models include the interaction between feeding and pathogens (Laurenson et al., 2011; Sandberg et al., 2006), and interactions between parasite 
burden and feed intake (Fox et al., 2013). There is a need to expand these models to better incorporate the relationships between feed nutritional value, digestion, health and productive functions, and resilience to pathogens (Doeschl-Wilson et al., 2008).

\section{Priorities}

A review of current knowledge of the relationships between nutrition and health, and the options for incorporating this information into nutritional models is required. This should include an investigation of the potential to translate pathogen variables into general concepts currently used in such models. The review should include previous work on the aspects of feed nutritional value and animal metabolism associated with disease prevention and improved resilience, in order to understand which types of data are most important to collect from experimental researchers and from crop and grassland models.

\section{Genetics and health}

Breeding for increased livestock resilience to climate related changes in environment and disease is an important component of adaptation and may also reduce GHG emissions (Wall et al., 2010). However, there are often trade-offs to overcome, exemplified by the inverse relationship between livestock resilience to high temperatures and productivity (Collier and Gebremedhin, 2015). For dairy cattle, random regression models have been used to investigate resilience in productivity and health under high THI levels (Carabaño et al., 2014; Hammami et al., 2014) e.g. linking genetic variation to traits such as somatic cell scores (as a proxy for udder health), milk fatty acids (Hammami et al., 2015) and conception rate and semen characteristics (Al-Kanaan et al., 2015; Brügemann et al., 2013). Similarly, a number of studies have investigated the effects of breeding programmes on resistance or resilience to pathogens (Doeschl-Wilson et al., 2008; Mavrot et al., 2015). Anacleto et al. (2015) used a combination of quantitative genetic modelling and Bayesian techniques to estimate the genetics of both resilience and infectivity of hosts, offering a new direction in identifying animals with high genetic risk in relation to disease. Despite these advances, the development of statistical approaches for relating genetic variation to phenotypic traits and to disease resilience and infectivity is still considered a challenge (Brooks-Pollock et al., 2015). In the context of predicting future disease spread based on data on pathogen-host interactions in current ranges, it is also important that models account for the genetic resilience of current 
host populations, which may not be shared by livestock in areas of potential invasion under climate change (Lloyd-Smith et al., 2015).

\section{Priorities}

Modelling advances in this area depend on identifying and filling gaps in experimental data relating to phenotypes and heritability in different livestock species and on links between genotype, performance and environmental conditions across different regions. Modelling priorities thus include (i) developing more mechanistic models able to characterise the production effects of livestock adaptation to climate change, including morphological adaptations and physiological and metabolic responses (Collier and Gebremedhin, 2015) and (ii) developing models that can reveal trade-offs and synergies between breeding for reduced infectivity and resilience (to climate extremes and disease), and breeding for current or future expected economic value.

\section{Modelling pathogens and vectors}

4. Pathogen, vector and wildlife host ecology

For existing pathogens in a given region, climate-related changes in prevalence and intensity are key to understanding future impact (Fox et al., 2015b). Recent reviews have highlighted the lack of ecological knowledge about pathogens, vectors and wildlife hosts, and issues of bias in available data, e.g. as a result of better recording of pathogen presence in more populated areas, or in places where expert collectors are based (Purse and Golding, 2015) (Challenge 11). Buhnerkempe et al. (2015) provide a comprehensive overview of the challenges to modelling disease ecology in multi-species systems. Here, elements most related to the impacts of climate change on ecology are considered. Assumptions about pathogen, vector and wildlife host ecology must take into account the adaptive responses of these species to environmental change and control measures, especially where climate change brings different pairings of pathogens (or potential vectors) and wildlife hosts into contact (Purse and Golding, 2015). The nature of (and changes in) transmission between wildlife hosts and livestock can be hard to unpick due to a lack of data on host infections, historic dogma (Brooks-Pollock et al., 2015) and complexities such as potential feedbacks between control measures, their ecological effects and transmission risks (Godfray et al., 2013). In a recent review of distribution models, Purse and Golding (2015) considered approaches for 
incorporating ecological information into such models based on comparisons of species distribution data to identify relationships, which require careful statistical evaluation to avoid errors in interpreting correlations. Flexible Bayesian approaches can be used to elaborate relationships better between large numbers of environmental and climatic variables (Wilson et al., 2013) and such approaches can be valuable tools for modellers as computing power increases (Ward and Lewis, 2013). For locations and species where data are available, the use of mechanistic models, including detailed representations of pathogen life-cycles, has revealed the potential importance of extreme weather events (Rose et al., 2015) and climatic thresholds (Fox et al., 2015b) for outbreaks, suggesting that observed relationships between pathogens, vectors and the environment may alter under climate change conditions.

\section{Priorities}

To improve the characterisation of pathogen, vector and wildlife host ecology under climate change, there is a need for more process-based modelling of pathogens and their vectors, grounded on improved ecological understanding. A first step to advance modelling in this field would be to collate an inventory of livestock pathogens, their known and potential hosts/vectors and current understanding of the ecology of each, including their likely sensitivity to climate change. The inventory could be compared with characterisations of these species in models, in order to highlight the most important gaps in current modelling.

\section{Pathogen and vector spread}

Models of pathogen and vector spread can be used to predict the likely progress of outbreaks and can be either developed during the early stages of such outbreaks or prepared in advance (Purse and Golding, 2015). Modelling is also used to predict pathogen and vector spread under future environmental conditions, e.g. through mechanistic modelling of parasite infection (Caminade et al., 2015; Fox et al., 2015a; Rose et al., 2015). Many distribution models used for predicting the progress of current outbreaks are empirical because such models can be developed fast and are easy to apply (Purse and Golding, 2015). However, even for longer term predictions, there are often not sufficient data to run more detailed mechanistic models (Cornell, 2005) (Challenge 11). Nevertheless, such models have provided important insights into the spread of vectors of human diseases (e.g. malaria) under climate change (Parham et al., 2015) indicating the value of these approaches where data are available. 
Through changes in pathogen and vector distribution, climate change brings the risk of outbreaks of novel pathogens, for which data and ecological information might be limited. In some cases, their spread can be modelled using data from similar, better understood, species (Gubbins et al., 2014b). However, given the complexity related to predicting species invasiveness in new environments (Moravcová et al., 2015), information about the target species itself is important in reducing uncertainty surrounding predictions. Lloyd-Smith et al. (2015) considered priorities for modelling the emergence of novel human pathogens; these are also relevant for the emergence of novel livestock pathogens and include better modelling of cross-species transmission force and accounting for host immunity in predictions of future spread (see also challenge 16).

Another major issue is in the interpretation of data on the ranges of current pathogen and vector species. Even accurate data may reflect non-climatic constraints on spread (e.g. topographical barriers or limits to host distribution) rather than climatic limitations, and might therefore be unsuitable for predicting the potential for future spread (Purse and Golding, 2015).

\section{Priorities}

General priorities recently identified for distributional models would also support more effective modelling of pathogen and vector spread under climate change. These include the need for improved modelling of transmission patterns and stochasticity (Roberts et al., 2015), and the incorporation of non-linear processes (Fox et al., 2015b), such as the importance of 'super spreaders' in disease outbreaks (Roberts et al., 2015) and changes in the rate of infection as outbreaks scale up (Brooks-Pollock et al., 2015). Although modelling by Ducheyne et al. (2011) incorporated information relating vector movement to environmental conditions, many pathogen/climate interactions are not yet modelled. As described in Challenges 4-5, Bayesian approaches represent a potentially important tool for investigating these complex interactions.

Progress in this field will be dependent to a large extent on new research and data collection (Baylis, 2013) (Challenge 9). The creation of an inventory of pathogen and vector ecology and of the models developed for each species (Challenge 4) is also important in relation to this challenge. The resource could be used to highlight known and potential relationships between species and climatic conditions, and to identify cases where models for one species 
might be adapted to characterise the spread of others. Finally, predicting the likely responses of species to changed conditions has long been considered by ecologists in the context of species invasions (Moravcová et al., 2015), demonstrating the potential for inter-disciplinary cooperation in this area.

\section{Modelling impacts of poor health}

6. Economic impacts of health on production

Better understanding the costs of health conditions is important in assessing the impacts of climate related changes in health. Farm scale costs can arise directly from poor health, or from health-related changes in reproductive efficiency and subsequent impacts on replacement rates (Dijkhuizen et al., 1995). A number of studies have modelled the farmscale costs of specific health problems in cattle, such as for bovine viral diarrhea (Smith et al., 2014), Johne's disease (Bennett et al., 2012; Garcia and Shalloo, 2015), subclinical ketosis (Raboisson et al., 2015), lameness (Huxley, 2013) and 34 endemic livestock diseases in the UK (Bennett and Ijpelaar, 2005). SimHerd (http://www.simherd.com/index.php/langen/home) models the production effects of a range of health conditions in dairy cattle, and can be used to quantify the impacts of management change, while economic modellers have calculated marginal abatement cost curves (MACC) to assess intervention costs relating to ten endemic health conditions affecting cattle in the UK (Elliott et al., 2014). However, most studies of ruminant systems focus on cattle and cover only part of the chain of causality from the impact of environmental conditions on livestock health to the consequences for final systemic outputs.

\section{Priorities}

An inventory of pathways via which climate change could affect livestock productivity and product quality would provide a useful framework within which to review systematically the capacity of models to characterise the biophysical processes underlying health impacts on production. Although an initial overview of climate change impacts has been presented (Fig. 2) more detail, especially with regard to impacts on physiological processes within the animal, is required. Economic models need to present accurate assessments of disease-related costs, and how they may change under future climate conditions, in order to drive economically rational responses; Brooks-Pollock et al. (2015) emphasize the importance of 
bringing together stakeholders, policy-makers and the public to find a universally agreed measure of costs, taking into account economic impacts at farm, local and national levels. Incorporating externalities (social and environmental costs) is also important to ensure optimal decision-making (Meier et al., 2015). Outputs from recent networking activities such as the NEAT project (Networking to enhance the use of economics in animal health education, research and policy-making in Europe and beyond) (http://www.neatnetwork.eu/project/overview) provide a basis for developing a better understanding of the economics of animal health.

\section{Impacts of health on GHG emissions}

Given the adverse effects of ill-health on productivity (Kyriazakis, 2014) (see Challenge 6) it can be expected that disease will increase GHG emission intensity. However, although there is much research and modelling of GHG emissions from livestock systems, only a few studies (Özkan et al., 2015a; Skuce et al., 2016; MacLeod et al., Unpublished results) have quantified the impacts of livestock ill-health on these emissions. Garnsworthy (2004) modelled the impacts of fertility and herd replacements on GHG emissions, but this model did not consider the impacts of poor health on fertility. More recently, Williams et al. (2013) used a systems-based Life Cycle Assessment (LCA) approach to quantify the impacts of different diseases on GHG emissions from cattle, highlighting the potential of this method not only to quantify disease impacts, but also to consider interactions between different health conditions and interventions (see also Challenge 9). There is also a lack of knowledge about the impacts of different health treatments on GHG emissions (Williams et al., 2013), although recent experimental work (Kenyon et al., 2013) has begun to address this issue.

\section{Priorities}

Several simulation models predict the effects of ill-health on livestock performance (see Challenges 2 and 6), providing a starting point from which to improve the characterisation of health impacts on GHG emissions. A review of current data is required, with an initial focus on the different effects of specific health conditions on GHG emissions intensity, in order to identify those which have the greatest impact. This review would lay the foundation for investigation and modelling of the consequences of disease control measures on emissions.

\section{Modelling interactions and management}


8. Land use change (LUC) and health

The future distribution of livestock populations, the nature of production systems, and the evolution of trade flows will have a great influence on how climate change and pathogen spread and intensity affect livestock (Ghahramani and Moore, 2013; Lara and Rostagno, 2013; Nardone et al., 2010). As a result, linking LUC modelling to pathogen modelling is important in enabling disease risk and hazard to be brought together in predictions of disease impacts (Muthukrishnan et al., 2015). While economic models focus on how climate and socio-economic change may alter future land use based on the profits accruing to different management options (Audsley et al., 2014), distribution modelling focuses on relationships between pathogens, vectors, their environment and climatic conditions. Advances in geospatial technologies (such as geographic information systems and remote sensing) allow the collection of high resolution land cover data. These can be used in models to create disease risk maps, by linking knowledge of pathogen and vector ecology to indices of vegetation cover, estimates of environmental moisture and climate change predictions (Jamison et al., 2015). One element of complexity is that associations between pathogens, vectors and habitat may cause high variation in abundance across landscapes (Kluiters et al., 2013); local scale investigations of such variation can be used to infer generalised habitat associations and allow predictions of abundance at larger scales based on geospatial land cover data. Modelling of the spatio-temporal distribution of biting midges suggests that adding distance variables can improve predictive value in comparison to the use of environmental variables only, reflecting seasonality in the role of habitat in species spread (Peters et al., 2014).

\section{Priorities}

Inter-disciplinary approaches are required to explore the potential effects of interactions between the ecological responses of pathogens and vectors to climate change, and LUC driven by climatic and socio-economic change. These approaches could highlight disease hot spots in areas of expected future livestock production. Understanding disease risk under these conditions will also need to take into account ecological interactions which are not currently modelled (Jamison et al., 2015). Developing models combining predictions of heat stress risks under climate change with economic LUC modelling, might represent a methodological stepping stone towards modelling similar interactions for pathogenic disease, where pathogen and vector ecology add another level of complexity. A first step for such interdisciplinary 
approaches would be to compare current LUC model predictions with maps of disease and heat stress risk under climate change.

9. Interactions between health conditions, pathogens and interventions

While most current models focus on a single health issues, health conditions may interact with each other, affecting treatment efficacy and disease outcomes (Ezenwa and Jolles, 2015). There are also interactions between health conditions, pathogens and interventions for prevention or treatment, e.g. the potential confounding effects of liver fluke infection on tuberculosis testing (Claridge et al., 2012; Flynn et al., 2007). Such interactions are important to understand in order to better predict the effects of changing climate and related mitigation and adaptation measures.

\section{Priorities}

There is a need to review research into these complex interactions, including the development of a typology of interactions between different health conditions and pathogens, and a review of interventions, their efficacy and interactions between them. In collating this information, the knowledge of veterinarians, farmers, farm advisors, economists and other stakeholders needs to utilised, in order to ensure that modelling priorities align with societal needs. The aim is to understand the most important interactions between these variables in terms of animal health and to identify gaps in knowledge, to support and focus modelling advances.

\section{Adaptation and mitigation strategies}

As the descriptions of other challenges show, modelling livestock systems are complex, and incorporating adaptation and mitigation scenarios adds a further level of complexity. Although existing empirical models can be used to predict some changes in livestock health associated with environmental variation (Skuce et al., 2013), such approaches cannot directly capture the effects of farm- and policy level strategies and their implementation over time. For economic modelling of the impacts of adaptation and mitigation strategies, it is essential to understand both the costs of health problems (e.g. welfare, productive, environmental and economic), and the cost, efficacy and sustainability of the interventions used to control or prevent them (see also Challenge 7). As the likely effects (and extent) of climate change vary across different socio-economic and emissions pathways, models of cost and benefit need to provide a coherent spread of predictions (Shrestha et al., 2013; Stainforth et al., 2005) in 
order to assess the robustness of different strategies across a range of plausible scenarios (Leclère et al., 2014). Models also need to characterise the uncertainties associated with the uptake of adaptation strategies (Challenge 18). If these factors can be addressed, information about the expected average costs and benefits of different strategies can be incorporated into economic modelling of farms, assuming the impacts of each strategy will be as previously observed.

Estimates of the costs and benefits of climate-driven adaptation (Moran et al., 2013; Oliveira Silva et al., 2016; Shrestha et al., 2014; Wreford et al., 2015) and (using MACCs) mitigation (Elliott et al., 2014; Moran et al., 2011) have been presented for the livestock industry, but these approaches are heavily reliant on assumptions due to lack of data at appropriate scales. Beyond the economics of adaptation and mitigation, mechanistic modelling of the underlying biophysical processes by which mitigation and adaptation measures affect systems is essential to making farm-centric predictions for decision support, and for evaluating the likely accuracy of economic models under climate change conditions at different scales.

At the regional and global level some recent modelling studies have incorporated the impact of climate change on livestock. However, such studies only considered climate change effects on livestock systems arising through changes in input (e.g. feed) productivity and prices and how these may drive systems transitions (Havlík et al., 2015; Özkan et al., 2015b; Weindl et al., 2015) and do not incorporate direct impacts of climate on livestock health. Regional scale studies incorporating the effects of environment on livestock production are only available for a few regions (Gauly et al., 2013) and those considering the effects of adaptation of such systems are very scarce.

\section{Priorities}

Better regional scale economic modelling of the consequences of climate and socio-economic change on livestock health, including adaptive responses, will be important for providing policy level information. This must be underpinned by a better understanding of these processes at the farm scale, mechanistic modelling of the bio-physical processes underlying adaptation and mitigation impacts, and evaluation of empirical relationships and assumptions (Challenge 14). 
The collation of information on adaptation and mitigation options associated with different health conditions, their efficacy and the capacity to model their implementation is a priority in this area. This should go alongside a review of the different aspects of cost and benefit related to health (Challenge 6). This information would provide a basis from which to develop models better able to predict outcomes, trade-offs and synergies between different strategies (Eory et al., 2014). Links with other disciplines to understand potential interactions between measures relating to health and pathogens, and those focused on other aspects of production, will also be important.

\section{Data and evaluation}

\section{Data quality}

Data availability and quality vary across the range of focus species, systems and purposes covered by health and pathogen modelling and also between countries (Challenge 15). Models requiring different amounts of data can be developed and applied to answer any given question (Gubbins et al., 2014a). The type of model used is therefore determined by the purpose of the modelling, how quickly outputs are required (Purse and Golding, 2015), and by the availability of data. For poorly resourced areas and less researched diseases, lack of data and ecological understanding are likely to be the limiting factors (Brooks-Pollock et al., 2015) while for developed countries and well researched species, limiting factors may be more often related to the purpose and urgency of the application. In general, information relating the spread, ecology and behaviour of pathogens and vectors to environmental factors may be derived from combined data from different species, be based only on laboratory experiments (Parham et al., 2015) or suffer problems of bias relating to survey effort and method (Purse and Golding, 2015). The availability of large amounts of detailed data can present different challenges. For example, the daily records of livestock movement, birth and death in some European countries present issues relating to data synthesis, differences in scale between different data types, and usage in tractable models (Brooks-Pollock et al., 2015). Recent advances include the development and use of big data models to identify control strategies for infectious diseases (Dawson et al., 2015).

\section{Priorities}


For different areas of modelling, data requirements include (i) new field studies, (ii) betterco-ordinated surveillance and (iii) the collection and collation of data from different regions to inform predictions about local climate change impacts where environmental conditions go beyond previously known ranges.). In this context, better communication about data between modellers, experimental researchers and stakeholders was considered vital to improve data standards and provision, including the development of stronger links to groups such as veterinarians who collect (or are in a position to collect) required data. To facilitate improved communication, modellers need to describe and prioritise the types of data required (Kragt et al., 2013), including which diseases, variables and scales they are needed for. The creation of a model typology (Challenge 13) would allow the mapping of data requirements onto model types. Data gaps could then be identified across models, farming systems, species and nations. Such a resource could also facilitate the development of guidelines for data providers, including collection protocols and benchmarks. To facilitate the collection of high quality data and to reduce sampling bias, new and improving survey techniques, such as geospatial approaches (Jamison et al., 2015) and vehicle-based arthropod sampling (Sanders et al., 2012) should be tested and applied. Advances in remote sensing technology and Wi-Fi remote control for farm-level data collection are foreseen to be important in this respect, and further development of cost-effective, easy-to-use recording systems for management and treatment data are also required.

In fields such as crop modelling, agreed minimum data standards for model use have been developed, with ranking systems to indicate data quality (Kersebaum et al., 2015); similar systems could be developed for the livestock health modelling community. Finally, for different model types, the sensitivity of model outcomes to the use of data at different scales needs to be tested to assess which gaps in data are most important to fill, and the extent to which scaling and gap-filling software can compensate for missing data. Data uncertainty can also be modelled when there is a lack of representative data, or where data may contain inaccuracies (Huijbregts et al., 2001).

\section{Data accessibility}

As the climate changes, efficient sharing of data about the impacts of novel conditions, and the responses of pathogens and vectors becomes ever more important. The data required for modelling livestock health and pathogens are held by a range of organisations, such as 
slaughterhouses and agricultural levy boards. As a result, they can be difficult to locate, and once found may not be freely available. Data owners may charge for their use, or be restricted from sharing information by data protection regulations (e.g. when data include information that would identify specific farms). Even when data are gathered and held by research institutes, there may be no, or limited contact between these institutes and modellers working in other organisations, while data held in different countries can be hard to locate.

\section{Priorities}

An initial priority in this area would be to review existing data-gathering and sharing initiatives, such as the epidemiological and vector records reviewed by Purse and Golding (2015) and wider resources such as the Open Data Journal for Agricultural Research (ODjAR) (www.ODjAR.org), GenBank (Bilofsky and Christian, 1988) and the Global Biodiversity Information Facility (www.gbif.org) (Wieczorek et al., 2012) in order to share information about these initiatives within the modelling community, and to engage with them to ensure that the requirements of modellers are considered. The Data Driven Dairy Decisions for Farmers (4D4F) project is developing a network of dairy farmers, sensor technology suppliers, data companies, agricultural advisors and researchers to use sensor data to support farm level decision making. Lessons may also be learned from other disciplines trying to improve data sharing (Hampton et al., 2013). The ultimate aim is to ensure that modellers have full information about available data, with meta-data and data freely accessible and easily searchable. An inventory of the rules and regulations controlling the use of data relevant to modelling livestock health in different countries would help to identify potential improvements to regulatory frameworks, and options for harmonising such frameworks across countries. Political support will be required to ensure better data availability for researchers in areas where there are currently legal or practical limitations.

\section{Terminology and measurements}

Differences between countries and research groups in measurement methods and terminology hinder the comparison and use of data and modelling outcomes. Examples include national differences in the definition and calculation of thermal indices and feed nutritional value (Bohmanova et al., 2007; Hahn et al., 2009; Hammami et al., 2013) and unique national keys for specific livestock health problems (Christen et al., 2015). A consistent framework for phenotypic trait description is also required to enable newly discovered traits and subclinical 
health problems to be robustly characterized in models. This aim is advanced by projects such as GPlusE (www.gpluse.eu) which are developing ontologies of biological (including health-related) traits relevant to dairy production.

\section{Priorities}

To begin to standardise measurements and terminology, an initial step would be to collate a list of the measurements, calculations and terms commonly used to describe variables in health and pathogen modelling. Existing resources, such as the International Committee for Animal Recording (ICAR) Recording Guidelines (www.icar.org/pages/recording_guidelines.htm) (Stock et al., 2013) could then form the basis for discussions to develop common measurements for use in modelling. In relation to livestock responses to high temperatures, agreed definitions of stress, stress responses and environmental conditions will be important (see Challenge 1). There is also a need to develop a typology of the range of models relating to livestock health, in order to facilitate better communication between modellers, experimental researchers and the wider scientific community.

\section{Validation of empirical relationships}

Rather than modelling every mechanistic process in a system, many models represent some processes with empirical relationships. To ensure reliability and utility, these empirical relationships must be based on a proper understanding of the mechanisms represented (Rose et al., 2015). This is particularly important in the context of climate change, which may alter some of these empirical relationships.

Most models simulating the effects of livestock health on production have used treatment data or well established indicators, like somatic cell count in milk, as proxies for health status (Fourichon et al., 1999; Østergaard et al., 2005). The efficacy of such proxies in representing underlying health problems needs to be tested and improved. Hence, the identification of previously unrecognized subclinical conditions and the development of new indicators are important advances for modelling how health conditions affect GHG emissions (Moyes et al., 2013; Raboisson et al., 2014). Among new indicators under development, Dehareng et al. (2012) and Vanlierde et al. (2015) have identified the potential to predict individual methane 
emissions of cattle directly from analysis of milk mid-infrared spectra, using the relationship between such spectra and THI impacts on milk quality.

\section{Priorities}

To improve the empirical characterisation of relationships in models, a review is needed to assess the extent to which current representations are based on an understanding of underlying mechanisms. This should include all modelling related to animal health under climate change, from farm to regional scales, and would serve to reveal knowledge gaps, identify cases where mechanisms are known but not utilised, and to assess options for improvement.

\section{Model scope and relevance}

\section{Variation in capacity between farming systems and nations}

Even within Europe, data and modelling capacity vary, and extensive and economically marginal systems are often under-researched. Parameterising different systems for modelling requires quantification of farm characteristics, necessitating a common understanding of those characteristics in order to identify relevant data. Although standardized data for climatic variables are currently accessible for most regions of the world (Hijmans et al., 2005), data on crop and livestock productivity from different countries may not be easily comparable. Issues include variation in data quality and lack of information about the management regimes from which data arose. Data resources are often focussed on notifiable diseases with the greatest impacts on trade (Purse and Golding, 2015). Grace et al. (2015) highlight the lack of information on animal diseases in developing countries, where populations are most vulnerable to the impacts of pathogen outbreaks. In some of these countries, basic information on agricultural systems may not be collected, and modelling may not be used for predicting disease risks or directing policy (Brooks-Pollock et al., 2015). In the short term, modelling approaches which can cope with sparse datasets (Gubbins et al., 2014a) can provide predictions about health and pathogens in these countries, while advances in geospatial surveying techniques enable increasingly fine-scale observations of environmental variables and land use (Jamison et al., 2015) providing more, and higher quality data to work from. Longer term, use of such approaches can direct field work and 
monitoring to most efficiently use scarce resources to gather information (Lloyd-Smith et al., 2015).

\section{Priorities}

Developing a typology of farming systems for use across the modelling community would represent a big step forward, and could build on existing typologies that characterise European systems (European Commission, 2008; Herrero et al., 2013; Seré et al., 1995). Such a classification would complement and support the development of 'fit-for-purpose' models (Challenge 17) and facilitate easier comparisons of models used in different systems, with a view to developing flexible models able to work across systems and regions. Work has also been undertaken to develop procedures for updating values in existing models in a consistent way across countries (Gerber et al., 2013; Havlik et al., 2015; Jayet et al., 2015; Louhichi et al., 2015), representing significant progress in this area. Crop and grassland modelling communities have developed model inter-comparison protocols to allow model capacity to be evaluated and improved, including in their application to systems and regions beyond that for which they were developed (Kollas et al., 2015; Sándor et al., 2016; von Lampe et al., 2014). By following a similar pathway, health and pathogen models can build the capacity to compare (and learn from) models used across the world in order to develop global capacity in livestock health and pathogen modelling.

16. Spatial and temporal scales

Buhnerkempe et al. (2015) and Brooks-Pollock et al. (2015) identified the need to improve how small-scale processes (at animal or herd level) are incorporated into modelling at larger scales, given that patterns and variation in such processes can have an important impact on large scale predictions. For example, local environmental variables can affect predictions of pathogen and vector transmission and spread (Challenge 5), and non-linearity in transmission can produce misleading estimates of control strategy efficacy if not taken into account (Matthews et al., 2013). Micro-simulation approaches applied at large scales (Ferguson et al., 2006) and scaling frameworks (Szmaragd et al., 2009) have been developed for some pathogens, and these could potentially be applied to other species. However, their application requires substantial data, and simpler approaches may be more cost effective, depending on the purpose of the modelling (Gubbins et al., 2014a). More simply, empirical models can be validated through understanding of mechanistic processes (Challenge 14), and can in turn 
reveal novel relationships for further investigation of mechanistic drivers (Kipling et al., 2016a).

An alternative to incorporating small scale processes into large scale models is the linkage of models or their outputs. However, across different scales, models are likely to characterise processes at different levels of temporal resolution, making even 'soft' linkage of outputs/inputs difficult. Even within a single scale of modelling, it can be challenging to capture both acute and chronic impacts of a pathogen or environmental variable and their interactions. Heat stress, for example, has impacts in the short term (e.g. within hours) and over longer time periods through acclimation and increased resilience (between generations), as well as having varying impacts according to the life-stage of affected animals (Renaudeau et al., 2012; Silanikove, 2000). For pathogen infections, changes in host immunity over time are considered in relatively few models (Fox et al., 2013) although they can affect disease spread and lead to changes in the level of economic impact over the years following an initial outbreak. Processes such as superinfection (where recovering animals are infected by a new strain of a pathogen) are often ignored (Roberts et al., 2015). The evolution of pathogens and their vectors, and their adaptive responses to climate change are also important to understand (Challenges 4 and 5). Finally, temporal factors need to be considered when incorporating management and policy responses to climate change into modelling. Although some temporal aspects are captured in models in which livestock move between age groups based on specified parameters (Robins et al., 2015) or through the integration of dynamic bio-physical models with economic modelling of daily changes in production level (Eory et al., 2014) the time required for decisions to be enacted is often overlooked in current modelling (Morgan, 2013).

\section{Priorities}

To build capacity to incorporate a range of spatial and temporal scales into models, recent reviews of the acute and chronic health impacts of pathogens (Palmer and O'Connell, 2015; Vanderhaeghen et al., 2014) and environmental conditions (Collier and Gebremedhin, 2015; Nardone et al., 2010) on livestock need to be collated, and the extent to which they are incorporated into current models ascertained. Opportunities for modelling based on data from new 'real time' sampling methods need to be systematically considered. In relation to spatial scaling, the livestock pathogen and health modelling community can benefit from advances 
in crop modelling (Ewert et al., 2014) and other research fields, in order to develop and assess the merits of different options for progress.

\section{Fit-for-purpose models}

It is important that models dealing with livestock health and pathogens meet stakeholder requirements, providing outputs at relevant scales and levels of accuracy, and operating with an appropriate degree of detail. In some cases, e.g. in supporting animal health decision making, it has been shown that model outputs often differ from the initial demands of stakeholders (Singer et al., 2011). This may stem from poor communication (see also Challenge 18), a lack of underlying knowledge, or models that are not adaptable to the needs of specific applications. Reeves et al. (2011) reviewed approaches for epidemiological model evaluation, highlighting the importance of clearly stating model purpose, limits and assumptions, and involving stakeholders in validation processes to ensure evaluation is related to fitness for purpose.

\section{Priorities}

Given the diversity of modelling related to livestock health, the development of an inventory and typology of models (see also Challenge 13), synthesizing and building on current reviews, would be an important step towards clarifying model capabilities and limitations. This resource should be available in an accessible format for stakeholders, to enable them to identify the most appropriate tools to deal with specific challenges (Voinov et al., 2016). It should include information about the systems, scales, target species (pathogens and hosts) and output parameters for which each model has been validated. Gaps in the information available for different models would also be highlighted, allowing a focus on specific challenges to sharing and comparing current models. From the information so collated, options could be explored to make models more adaptable for different uses and for use together in order to provide a roadmap towards adaptable, integrated modular modelling systems Modular model components can be developed using common platforms such as General Algebraic Modelling System (GAMS) and R routines. Such platforms make modular components easy to identify, modify, validate and access for integration for specific applications. A starting point for the development of such a collaborative framework would be to review the approaches taken in other fields of agricultural modelling, e.g. the Biophysical Models Applications (BioMA) framework (http://bioma.jrc.ec.europa.eu) and 
RECORD (Bergez et al., 2013). Investigating how integrated modelling approaches, e.g. Integrated Environmental Modelling (Laniak et al., 2013) may be applied in modelling livestock health would also be beneficial. A supportive framework of resources and incentives is thus required to enable researchers to develop links between disciplines and nations (Kipling et al., 2016a). The long-term development of networking initiatives such as MACSUR, GRA, and the Agricultural Model Improvement Programme (AgMIP) (http://www.agmip.org) provide arenas for the creation and use of these types of resource for livestock health and pathogen modelling.

\section{Stakeholder involvement}

Farm level, costs of disease mean that stakeholders are often easily motivated to engage with researchers (Wilson et al., 2013). Modelling in this area can therefore be important in increasing understanding of climate change impacts among stakeholders, with the aim of improving the uptake of mitigation and adaptation strategies (Jonsson et al., 2015). However, using modelling to direct control strategies during outbreaks can be subject to intense scrutiny, making trust building and collaborative development of models with stakeholders vital (Brooks-Pollock et al., 2015). Further, local level engagement can provide important information about local patterns of disease occurrence and spread that can direct research and surveillance efforts to hot spots (Purse and Golding, 2015). Such interactions may be particularly important in identifying changes in pathogen, vector, or host species ecology in the context of climate change. To ensure the relevance of models, stakeholders need to be engaged in the modelling process, either directly or through collaboration with social scientists to bridge inter-group gaps (Sterk et al., 2011).

Socio-economic scenarios are being developed to enable regional scale economic modelling to better represent stakeholder decisions at the societal level (Antle et al., 2013; Toma et al., 2013). However, at farm level many non-economic factors are known to affect decisions (e.g. farm location and type, farmers' skills, perceptions and availability to work) (Shrestha et al., 2015). A range of socio-psychological methods have been utilized to investigate stakeholder behaviour relating to a wide range of pathogens (Milne and Paton, 2015; Velde et al., 2015; Wauters and Rojo-Gimeno, 2014).

\section{Priorities}


Given the breadth of existing work on stakeholder engagement (Voinov and Bousquet, 2010), understanding could be enhanced by collating results from previous engagement exercises and associated literature (Fazey et al., 2014) and draw on experience from recent initiatives, such as the Epidemiology, Population health and Infectious Disease Control (EPIC) programme in Scotland. More accurate modelling of stakeholder decisions may also be aided by better monitoring of management choices, e.g. through the collection of data relating to these choices during current farm monitoring.

\section{DISCUSSION}

The range of challenges identified in this study reflects the diversity of health and pathogen modelling, with researchers differentiated by modelling approach and scale, by the systems and species they focus on, and by the specific applications of their modelling. The problem of climate change can be viewed as an arena (Clarke Adele, 1991) in which these different strands of modelling must interact in order to find solutions. By drawing out the aspects of current research most relevant to the climate change problem, the aim has been to reveal and explore the potential for inter-disciplinary progress, highlighting where approaches and interests in different scientific fields might be used in other contexts. Examples of these interconnections include the potential use of Bayesian approaches to explore complex interactions between multiple variables, the need to link up economic LUC and pathogen and vector distribution models to better predict future disease risk (Challenge 8), and the common interests of ecology and disease epidemiology in relation to invasive species/future pathogen spread (Challenges 4 and 5).

Underlying themes within many challenges included the need to create accessible, systematic inventories of modelling capacity and data, and for the more effective spread of best practice and new techniques both within the livestock health and pathogen modelling community, and across related disciplines. The data related challenges indicate that a more cohesive research community should include experimental researchers and stakeholders as well as modellers, to ensure that the vital relationship between data gathering, analysis and modelling is enhanced.

Networking and inter-disciplinary work entail costs as well as rewards (Siedlok and Hibbert, 2014) and modellers need to be supported by sufficient resources and appropriate organisational frameworks in order to develop capacity in this field of research. The engagement of researchers in this horizon-scanning exercise indicated an appreciation of the 
benefits of developing a more cohesive community of livestock pathogen and health researchers. Networking initiatives such as MACSUR and GRA have the potential to drive such developments, but only if the research environment is shaped to provides the time, space and funding to support sustained and long-term growth in capacity.

Although the collaborative approach taken here was successful in highlighting some key challenges in this field, the value of such exercises can be reduced by participant bias. To avoid such issues, a large and diverse group of experts was consulted (Pretty et al., 2010). Literature based validation and exploration of the views communicated by participants were used to add weight to the findings, and to add richness and new perspectives to the initial content.

\section{CONCLUSION}

This paper attempts to define a coherent set of challenges and research priorities for the diverse and complex field of modelling livestock health and pathogens in the context of climate change. It is hoped that this effort contributes to realising a more cohesive and outward-looking European research community in this field, so stimulating the best use of the diverse modelling approaches available across scientific disciplines and nations. The findings presented highlight the importance of properly funded, long-term modelling and research networks as platforms for the mutual learning required for tackling the complex challenges faced by the livestock sector in a climate change world.

\section{ACKNOWLEDGEMENTS}

This paper was supported by the FACCE-JPI knowledge hub Modelling European Agriculture with Climate Change for Food Security (MACSUR) and the Animal Health Network of the Global Research Alliance, with additional support from the Norwegian Research Council, SPW (Belgium), MSTI (Denmark), JÜLICH and BLE (Germany), MIPAAF (Italy), NCRD (Poland), INIA (Spain) and DEFRA, RESAS and BBSRC (UK), H2020 SUSFANS Grant Number 633692 (D. Leclère), ESEI UrbanZoo and CGIAR A4NH (T.P. Robinson). The authors would also like to thank two anonymous reviewers for their comments on the draft of this paper.

\section{REFERENCES}


Al-Kanaan, A., et al., 2015. Effects of heat stress on semen characteristics of Holstein bulls estimated on a continuous phenotypic and genetic scale. Livestock Science. 177, 15-24. 10.1016/j.livsci.2015.04.003.

Anacleto, O., et al., 2015. A novel statistical model to estimate host genetic effects affecting disease transmission. Genetics. 201, 871-884. 10.1534/genetics.115.179853.

Antle, J. M., et al., 2013. AgMIP's Transdisciplinary Agricultural Systems Approach to Regional Integrated Assessment of Climate Impacts, Vulnerability, and Adaptation. In Rosenzweig, C and Hillel, D. (Eds). Handbook of Climate Change and Agroecosystems: The Agricultural Model Intercomparison and Improvement Project Integrated Crop and Economic Assessments, Part 1. Imperial College Press, London. pp. 27-44.

ATF, 2013. Research and innovation for a sustainable livestock sector in Europe: Suggested priorities for support under Horizon 2020 to enhance innovation and sustainability in the animal production sector of Europe's food supply chains. Animal Task Force white paper.

ATF, 2014. Research and innovation for a competitive and sustainable animal production sector in Europe: Recommended priorities for support under Horizon 2020 in the 2016/2017 programme. 1st Addendum to the Animal Task Force white paper.

Audsley, E., et al., 2014. Interactively modelling land profitability to estimate European agricultural and forest land use under future scenarios of climate, socio-economics and adaptation. Climatic Change. 128, 215-227. 10.1007/s10584-014-1164-6.

Bareille, N., et al., 2003. Effects of health disorders on feed intake and milk production in dairy cows. Livestock Production Science. 83, 53-62. 10.1016/S0301-6226(03)00040-X.

Baumont, R., et al., 2004. A mechanistic model of intake and grazing behaviour in sheep integrating sward architecture and animal decisions. Animal Feed Science and Technology. 112, 5-28. 10.1016/j.anifeedsci.2003.10.005.

Baylis, M., 2013. Research gaps in understanding how climate change will affect arboviral diseases. Animal Health Research Reviews. 14, 143-146. 10.1017/S1466252313000145.

Bennett, R., Ijpelaar, J., 2005. Updated Estimates of the Costs Associated with Thirty Four Endemic Livestock Diseases in Great Britain: A Note. Journal of Agricultural Economics. 56, 135-144. 10.1111/j.1477-9552.2005.tb00126.x. 
Bennett, R., et al., 2012. Modelling of Johne's disease control options in beef cattle: A decision support approach. Livestock Science. 146, 149-159. 10.1016/j.livsci.2012.03.002.

Bergez, J. E., et al., 2013. An open platform to build, evaluate and simulate integrated models of farming and agro-ecosystems. Environmental Modelling \& Software. 39, 39-49. 10.1016/j.envsoft.2012.03.011.

Bernabucci, U., et al., 2014. The effects of heat stress in Italian Holstein dairy cattle. Journal of Dairy Science. 97, 471-486. 10.3168/jds.2013-6611.

Bertocchi, L., et al., 2014. Seasonal variations in the composition of Holstein cow's milk and temperature-humidity index relationship. Animal. 8, 667-674.

Bilofsky, H. S., Christian, B., 1988. The GenBank ${ }^{\circledR}$ genetic sequence data bank. Nucleic Acids Research. 16, 1861-1863.

Bohmanova, J., et al., 2007. Temperature-humidity indices as indicators of milk production losses due to heat stress. Journal of Dairy Science. 90, 1947-1956. 10.3168/jds.2006-513.

Bolin, C., et al., 2004. Emerging Zoonotic Diseases and Water. In Cotruvo, J.A. et al. (Eds) Waterborne Zoonoses, Identification, Causes and Control. World Health Organization, IWA Publishing, London. 19-25.

Brooks-Pollock, E., et al., 2015. Eight challenges in modelling infectious livestock diseases. Epidemics. 10, 1-5. 10.1016/j.epidem.2014.08.005.

Brügemann, K., et al., 2013. Application of random regression models to infer the genetic background and phenotypic trajectory of binary conception rate by alterations of temperature x humidity indices. Livestock Science. 157, 389-396. 10.1016/j.livsci.2013.08.009.

Buhnerkempe, M. G., et al., 2015. Eight challenges in modelling disease ecology in multihost, multi-agent systems. Epidemics. 10, 26-30. 10.1016/j.epidem.2014.10.001.

Caminade, C., et al., 2015. Modelling recent and future climatic suitability for fasciolosis in Europe. Geospatial Health; 9, 301-308. 10.4081/gh.2015.352.

Carabaño, M.-J., et al., 2016. Modeling heat stress under different environmental conditions. Journal of Dairy Science. 99, 3798-3814. 10.3168/jds.2015-10212 
Carabaño, M., et al., 2014. Modeling heat stress effect on Holstein cows under hot and dry conditions: Selection tools. Journal of Dairy Science. 97, 7889-7904.

CDCP, 2015. About One Health. Centers for Disease Control and Prevention, http://www.cdc.gov/onehealth/about.html.

Christen, A.-M., et al., 2015. Recording of claw and foot disorders in dairy cattle: current role and prospects of the international harmonization initiative of ICAR. In Kowlaski. Z. et al. (Eds), 2015. Performance Recording in the Genotyped World. Proceedings of the ICAR Technical Meeting, 10-12 June 2015, Krakow, Poland.

Claridge, J., et al., 2012. Fasciola hepatica is associated with the failure to detect bovine tuberculosis in dairy cattle. Nature Communications. 3. 10.1038/ncomms1840.

Clarke Adele, E., Social Worlds/Arenas Theory as Organizational Theory. In: D. R. Maines, (Ed.), Social Organization and Social Process. Essays in Honor of Anselm Strauss. Aldine de Gruyter, New York, 1991, pp. 119-158.

Collier, R. J., Gebremedhin, K. G., 2015. Thermal biology of domestic animals. Annual Review of Animal Biosciences 3, 513-532. 10.1146/annurev-animal-022114-110659.

Cornell, S., 2005. Modelling nematode populations: 20 years of progress. Trends in Parasitology. 21, 542-545. 10.1016/j.pt.2005.08.019.

Dawson, P. M., et al., 2015. Epidemic predictions in an imperfect world: modelling disease spread with partial data. Proceedings of the Royal Society of London B: Biological Sciences. 282, $20150205.10 .1098 / \mathrm{rspb} .2015 .0205$.

Dehareng, F., et al., 2012. Potential use of milk mid-infrared spectra to predict individual methane emission of dairy cows. Animal. 6, 1694-1701. 10.1017/S1751731112000456.

Dijkhuizen, A. A., et al., 1995. Economic analysis of animal diseases and their control. Preventive Veterinary Medicine. 25, 135-149. 10.1016/0167-5877(95)00535-8.

Doeschl-Wilson, A. B., et al., 2008. Exploring the assumptions underlying genetic variation in host nematode resistance. Genetics, Selection, Evolution. 40, 241-264. 10.1051/gse:2008001. 
Dorner, S. M., et al., 2006. Hydrologic modeling of pathogen fate and transport. Environmental Science \& Technology. 40, 4746-4753. 10.1021/es060426z.

Ducheyne, E., et al., 2011. A stochastic predictive model for the natural spread of bluetongue. Preventive Veterinary Medicine. 99, 48-59. 10.1016/j.prevetmed.2011.01.003.

Elliott, J., et al., 2014. Modelling the Impact of Controlling UK Endemic Cattle Diseases on Greenhouse Gas Emissions (Defra project AC0120).

Eory, V., et al., 2014. Linking an economic and a biophysical model to support farm GHG mitigation policy. German Journal of Agricultural Economics. 133-142.

European Commission, 2008. Commission Regulation (EC) No 1242/2008 of 8 December 2008 establishing a Community typology for agricultural holdings. Official Journal of the European Union. 2235/3-24.

Ewert, F., et al., 2014. Crop modelling for integrated assessment of risk to food production from climate change. Environmental Modelling \& Software. 72, 1-17. 10.1016/j.envsoft.2014.12.003.

Ezenwa, V. O., Jolles, A. E., 2015. Opposite effects of anthelmintic treatment on microbial infection at individual versus population scales. Science. 347, 175-177. 10.1126/science.1261714.

FACCE-JPI, 2012. Strategic Research Agenda.

Fazey, I., et al., 2014. Evaluating knowledge exchange in interdisciplinary and multistakeholder research. Global Environmental Change. 25, 204-220. 10.1016/j.gloenvcha.2013.12.012.

Ferguson, N. M., et al., 2006. Strategies for mitigating an influenza pandemic. Nature. 442, 448-452. 10.1038/nature04795.

Flynn, R. J., et al., 2007. Experimental Fasciola hepatica infection alters responses to tests used for diagnosis of bovine tuberculosis. Infection and Immunity. 75, 1373-1381. 10.1128/IAI.01445-06.

Fourichon, C., et al., 1999. Effects of disease on milk production in the dairy cow: a review. Preventive Veterinary Medicine. 41, 1-35. 10.1016/S0167-5877(99)00035-5. 
Fox, N. J., et al., 2015a. Modelling livestock parasite risk under climate change. Advances in Animal Biosciences. 6, 32-34. 10.1017/S204047001400048X.

Fox, N. J., et al., 2013. Modelling parasite transmission in a grazing system: The importance of host behaviour and immunity. Plos One. 8. e77996. 10.1371/journal.pone.0077996.

Fox, N. J., et al., 2015b. Climate-driven tipping-points could lead to sudden, high-intensity parasite outbreaks. Royal Society Open Science. 2, 140296-140296. 10.1098/rsos.140296.

Fox, N. J., et al., 2011. Predicting impacts of climate change on Fasciola hepatica risk. PLoS ONE. 6, e16126. 10.1371/journal.pone.0016126.

Garcia, A. B., Shalloo, L., 2015. Invited review: The economic impact and control of paratuberculosis in cattle. Journal of Dairy Science. 98, 5019-5039. 10.3168/jds.2014-9241.

Garnsworthy, P., 2004. The environmental impact of fertility in dairy cows: a modelling approach to predict methane and ammonia emissions. Animal Feed Science and Technology. 112, 211-223. 10.1016/j.anifeedsci.2003.10.011.

Gauly, M., et al., 2013. Future consequences and challenges for dairy cow production systems arising from climate change in Central Europe - a review. Animal. 7, 843-859. $10.1017 / \mathrm{s} 1751731112002352$.

Gerber, P., et al., 2011. Productivity gains and greenhouse gas emissions intensity in dairy systems. Livestock Science. 139, 100-108. 10.1016/j.livsci.2011.03.012.

Gerber, P. J., et al., 2013. Tackling climate change through livestock: a global assessment of emissions and mitigation opportunities. Food and Agriculture Organization of the United Nations (FAO).

Ghahramani, A., Moore, A. D., 2013. Climate change and broadacre livestock production across southern Australia. 2. Adaptation options via grassland management. Crop \& Pasture Science. 64, 615-630. 10.1071/cp13195.

Godfray, H. C. J., et al., 2013. A restatement of the natural science evidence base relevant to the control of bovine tuberculosis in Great Britain. Proceedings of the Royal Society of London B: Biological Sciences. 280, 1-9. 10.1098/rspb.2013.1634. 
Grace, D., et al., 2015. Climate and livestock disease: assessing the vulnerability of agricultural systems to livestock pests under climate change scenarios. CCAFS Working Paper no. 116. CGIAR Research Program on Climate Change, Agriculture and Food Security (CCAFS), Copenhagen.

Gubbins, S., et al., 2014a. Modelling the continental-scale spread of Schmallenberg virus in Europe: Approaches and challenges. Preventive Veterinary Medicine. 116, 404-411. 10.1016/j.prevetmed.2014.02.004.

Gubbins, S., et al., 2014b. Inferences about the transmission of Schmallenberg virus within and between farms. Preventive Veterinary Medicine. 116, 380-390. 10.1016/j.prevetmed.2014.04.011.

Hahn, G.L., et al., 2009. Thermal Indices and Their Applications for Livestock Environments. In DeShazer, J.A. et al. (Eds) 2009. Livestock Energetics and Thermal Environmental Management. ASABE, St Joseph, Michigan. pp. 113-130. $10.13031 / 2013.28298$.

Hammami, H., et al., 2013. Evaluation of heat stress effects on production traits and somatic cell score of Holsteins in a temperate environment. Journal of Dairy Science. 96, 1844-1855. 10.3168/jds.2012-5947.

Hammami, H., et al., 2014. Genotype x Climate interactions for protein yield using four European Holstein Populations. Article No. 30 in 10th World Congress on Genetics Applied to Livestock Production, Vancouver, Canada. https://asas.confex.com/asas/WCGALP14/webprogram/start.html.

Hammami, H., et al., 2015. Genetic analysis of heat stress effects on yield traits, udder health, and fatty acids of Walloon Holstein cows. Journal of Dairy Science. 98, 4956-4968. 10.3168/jds.2014-9148.

Hampton, S. E., et al., 2013. Big data and the future of ecology. Frontiers in Ecology and the Environment. 11, 156-162. 10.1890/120103.

Havlík, P., et al., 2015. Global Climate Change, Food Supply and Livestock Production Systems: A Bioeconomic Analysis. In Elbehri, A. (Ed.), 2015. Climate Change and Food Systems: Global Assessment and Implications for Food Security and Trade. FAO, Rome. 
Herrero, M., et al., 2013. Biomass use, production, feed efficiencies, and greenhouse gas emissions from global livestock systems. Proceedings of the National Academy of Sciences of the United States of America. 110, 20888-20893. 10.1073/pnas.1308149110.

Hijmans, R. J., et al., 2005. Very high resolution interpolated climate surfaces for global land areas. International Journal of Climatology. 25, 1965-1978. 10.1002/joc.1276.

Huijbregts, M. A., et al., 2001. Framework for modelling data uncertainty in life cycle inventories. The International Journal of Life Cycle Assessment. 6, 127-132. 10.1007/BF02978728.

Huxley, J. N., 2013. Impact of lameness and claw lesions in cows on health and production. Livestock Science. 156, 64-70. 10.1016/j.livsci.2013.06.012.

Jamison, A., et al., 2015. Spatial ecology, landscapes, and the geography of vector-borne disease: A multi-disciplinary review. Applied Geography. 63, 418-426. 10.1016/j.apgeog.2015.08.001.

Jayet, P., et al., 2015. The European agro-economic AROPAj model, INRA. Free access: www. versailles-grignon. inra. fr/economie_publique_eng/Research-work.

Jonsson, A. M., et al., 2015. Enhanced science-stakeholder communication to improve ecosystem model performances for climate change impact assessments. Ambio. 44, 249-255. $10.1007 / \mathrm{s} 13280-014-0553-4$.

Kenyon, F., et al., 2013. Reduction in greenhouse gas emissions associated with worm control in lambs. Agriculture 3, 271-284. 10.3390/agriculture3020271.

Kersebaum, K., et al., 2015. Analysis and classification of data sets for calibration and validation of agro-ecosystem models. Environmental Modelling \& Software. 72, 402-417. 10.1016/j.envsoft.2015.05.009.

Kipling, R. P., et al., 2016a. Modeling European ruminant production systems: Facing the challenges of climate change. Agricultural Systems. 147, 24-37. 10.1016/j.agsy.2016.05.007.

Kipling, R. P., et al., 2016b. Key challenges and priorities for modelling European grasslands under climate change. Science of The Total Environment. 566-567, 851-864. 10.1016/j.scitotenv.2016.05.144. 
Kipling, R. P., et al., 2014. Modelling livestock and grassland systems under climate change. In Hopkins, A. et al. (Eds), 2014. EGF at 50: The future of European grasslands. Proceedings of the 25th General Meeting of the European Grassland Federation, Aberystwyth University, Aberystwyth. pp. 97-99.

Kluiters, G., et al., 2013. Modelling the spatial distribution of Culicoides biting midges at the local scale. Journal of Applied Ecology. 50, 232-242. 10.1111/1365-2664.12030.

Kollas, C., et al., 2015. Crop rotation modelling-A European model intercomparison. European Journal of Agronomy. 70, 98-111. 10.1016/j.eja.2015.06.007.

Kragt, M. E., et al., 2013. Modellers' roles in structuring integrative research projects. Environmental Modelling \& Software. 39, 322-330. 10.1016/j.envsoft.2012.06.015.

Kyriazakis, I., 2014. Pathogen-induced anorexia: a herbivore strategy or an unavoidable consequence of infection? Animal Production Science. 54, 1190-1197. 10.1071/AN14431.

Lacetera, N., et al., 2013. Climate induced effects on livestock population and productivity in the Mediterranean area. Regional assessment of climate change in the Mediterranean. Advances in Global Change Research. 51, 135-156. 10.1007/978-94-007-5772-1_7.

Laniak, G. F., et al., 2013. Integrated environmental modeling: A vision and roadmap for the future. Environmental Modelling \& Software. 39, 3-23. 10.1016/j.envsoft.2012.09.006.

Lara, L. J., Rostagno, M. H., 2013. Impact of heat stress on poultry production. Animals. 3, 356-369. 10.3390/ani3020356.

Laurenson, Y. C. S. M., et al., 2011. In silico exploration of the mechanisms that underlie parasite-induced anorexia in sheep. British Journal of Nutrition. 106, 1023-1039. 10.1017/S0007114511001371.

Leclère, D., et al., 2014. Climate change induced transformations of agricultural systems: insights from a global model. Environmental Research Letters. 9, 124018-124031. 10.1088/1748-9326/9/12/124018.

Leclère, D., et al., 2013. Farm-level autonomous adaptation of European agricultural supply to climate change. Ecological Economics. 87, 1-14. 10.1016/j.ecolecon.2012.11.010. 
Lloyd-Smith, J. O., et al., 2015. Nine challenges in modelling the emergence of novel pathogens. Epidemics. 10, 35-39. 10.1016/j.epidem.2014.09.002.

Louhichi, K., et al., 2015. Individual Farm Model for Common Agricultural Policy Analysis (IFM-CAP). Institute for Prospective and Technological Studies, Joint Research Centre,

Matthews, L., et al., 2013. Predicting the public health benefit of vaccinating cattle against Escherichia coli O157. Proceedings of the National Academy of Sciences of the United States of America. 110, 16265-16270. 10.1073/pnas.1304978110.

Mavrot, F., et al., 2015. Effect of gastro-intestinal nematode infection on sheep performance: a systematic review and meta-analysis. Parasites \& Vectors. 8, 1-11. 10.1186/s13071-0151164-z.

McDowell, R. E., et al., 1969. Effect of heat stress on energy and water utilization of lactating cows. Journal of Dairy Science. 52, 188-194. 10.3168/jds.S0022-0302(69)86528-8.

Meier, M. S., et al., 2015. Environmental impacts of organic and conventional agricultural products - Are the differences captured by life cycle assessment? Journal of Environmental Management. 149, 193-208. 10.1016/j.jenvman.2014.10.006.

Milne, C., Paton, L., 2015. Changing farm practices: planning programmes for change Scottish Rural College. Rural Policy Centre Research Brief (RUC RPC RB 2015/10). Scottish Rural College, Edinburgh.

Moran, D., et al., 2011. Marginal abatement cost curves for UK agricultural greenhouse gas emissions. Journal of Agricultural Economics. 62, 93-118. 10.1111/j.14779552.2010.00268.x.

Moran, D., et al., 2013. Assessing the preparedness of England's natural resources for a changing climate: assessing the type and level of adaptation action required to address climate risks in the 'vulnerability hotspots'. Report to the Adaptation Sub Committee, Committee on Climate Change.(accessed 13.02. 14).

Moravcová, L., et al., 2015. Getting the Right Traits: Reproductive and Dispersal Characteristics Predict the Invasiveness of Herbaceous Plant Species. PLoS ONE. 10, e0123634. 10.1371/journal.pone.0123634. 
Morgan, E. R., 2013. Detail and the devil of on-farm parasite control under climate change. Animal Health Research Reviews. 14, 138-142. 10.1017/S146625231300011X.

Moyes, K., et al., 2013. Generation of an index for physiological imbalance and its use as a predictor of primary disease in dairy cows during early lactation. Journal of Dairy Science. 96, 2161-2170. 10.3168/jds.2012-5646.

Muthukrishnan, R., et al., 2015. Evaluating the role of landscape in the spread of invasive species: The case of the biomass crop Miscanthus $\times$ giganteus. Ecological Modelling. 317, 615. 10.1016/j.ecolmodel.2015.08.022.

Nardone, A., et al., 2010. Effects of climate changes on animal production and sustainability of livestock systems. Livestock Science. 130, 57-69. 10.1016/j.livsci.2010.02.011.

Oliveira Silva, R. d., et al., 2016. Increasing beef production could lower greenhouse gas emissions in Brazil if decoupled from deforestation. Nature Climate Change, 6, 493-497. 10.1038/nclimate2916.

Østergaard, S., et al., 2005. A stochastic model simulating pathogen-specific mastitis control in a dairy herd. Journal of Dairy Science. 88, 4243-4257. 10.3168/jds.S0022-0302(05)731118.

Özkan, Ş., et al., 2015a. Impact of animal health on greenhouse gas emissions. Advances in Animal Biosciences. 6, 24-25. 10.1017/S2040470014000454.

Özkan, Ş., et al., 2015b. Effect of climate variability on pasture-based dairy feeding systems in south-east Australia. Animal Production Science. 55, 1106-1116. 10.1071/AN14493.

Palmer, M. A., O'Connell, N. E., 2015. Digital dermatitis in dairy cows: A review of risk factors and potential sources of between-animal variation in susceptibility. Animals. 5, 512535. 10.3390/ani5030369.

Parham, P. E., et al., 2015. Climate, environmental and socio-economic change: weighing up the balance in vector-borne disease transmission. Philosophical Transactions of the Royal Society of London B: Biological Sciences. 370. 10.1098/rstb.2013.0551. 
Perry, B. D., et al., 2013. Current drivers and future directions of global livestock disease dynamics. Proceedings of the National Academy of Sciences. 110, 20871-20877. 10.1073/pnas.1012953108.

Peters, J., et al., 2014. Predicting spatio-temporal Culicoides imicola distributions in Spain based on environmental habitat characteristics and species dispersal. Ecological Informatics. 22, 69-80. 10.1016/j.ecoinf.2014.05.006.

Pretty, J., et al., 2010. The top 100 questions of importance to the future of global agriculture. International Journal of Agricultural Sustainability. 8, 219-236.

Purse, B. V., Golding, N., 2015. Tracking the distribution and impacts of diseases with biological records and distribution modelling. Biological Journal of the Linnean Society. 115, 664-677. 10.1111/bij.12567.

Raboisson, D., et al., 2015. The economic impact of subclinical ketosis at the farm level: Tackling the challenge of over-estimation due to multiple interactions. Preventive Veterinary Medicine. 122, 417-425. 10.1016/j.prevetmed.2015.07.010.

Raboisson, D., et al., 2014. Diseases, reproductive performance, and changes in milk production associated with subclinical ketosis in dairy cows: A meta-analysis and review. Journal of Dairy Science. 97, 7547-7563. 10.3168/jds.2014-8237.

Reeves, A., et al., 2011. Approaches for evaluating veterinary epidemiological models: verification, validation and limitations. Revue Scientifique et Technique (International Office of Epizootics). 30, 499-512.

Renaudeau, D., et al., 2012. Adaptation to hot climate and strategies to alleviate heat stress in livestock production. Animal. 6, 707-728. 10.1017/s1751731111002448.

Roberts, M., et al., 2015. Nine challenges for deterministic epidemic models. Epidemics. 10, 49-53. 10.1016/j.epidem.2014.09.006.

Robins, J., et al., 2015. Agent-based model for Johne's disease dynamics in a dairy herd. Veterinary Research. 46, 1-9. 10.1186/s13567-015-0195-y. 
Rose, H., et al., 2015. GLOWORM-FL: A simulation model of the effects of climate and climate change on the free-living stages of gastro-intestinal nematode parasites of ruminants. Ecological Modelling. 297, 232-245. 10.1016/j.ecolmodel.2014.11.033.

Sandberg, F., et al., 2006. A model for predicting feed intake of growing animals during exposure to pathogens. Journal of Animal Science. 84, 1552-1566.

Sanders, C. J., et al., 2012. Investigation of Diel Activity of Culicoides Biting Midges (Diptera: Ceratopogonidae) in the United Kingdom by Using a Vehicle-Mounted Trap. Journal of Medical Entomology. 49, 757-765. 10.1603/me11259.

Sándor, R., et al., 2016. Modelling of grassland fluxes in Europe: Evaluation of two biogeochemical models. Agriculture, Ecosystems \& Environment. 215, 1-19. 10.1016/j.agee.2015.09.001.

Semenza, J. C., 2015. Changes in Hydrology and its Impacts on Waterborne Disease. In Luber G., Lemery, J. (Eds), 2015. Global Climate Change and Human Health: From Science to Practice. Josey-Bass, San Francisco. pp. 103-135.

Seré, C., et al., 1995. World livestock production systems: current status, issues and trends. Consultation on Global Agenda for Livestock Research, Nairobi (Kenya), 18-20 Jan 1995. ILRI.

Shrestha, S., et al., 2015. Irish farms under climate change-is there a regional variation on farm responses? The Journal of Agricultural Science. 153, 385-398. $10.1017 / \mathrm{S} 0021859614000331$.

Shrestha, S., et al., 2013. Impacts of climate change on EU agriculture. Review of Agricultural and Applied Economics. 16, 24-39.

Shrestha, S., et al., 2014. Determining short term responses of Irish dairy farms under climate change. German Journal of Agricultural Economics. 63, 143-155.

Siedlok, F., Hibbert, P., 2014. The organization of interdisciplinary research: Modes, drivers and barriers. International Journal of Management Reviews. 16, 194-210. 10.1111/ijmr.12016. 
Silanikove, N., 2000. Effects of heat stress on the welfare of extensively managed domestic ruminants. Livestock Production Science. 67, 1-18. 10.1016/s0301-6226(00)00162-7.

Singer, A., et al., 2011. Reviewing model application to support animal health decision making. Preventive Veterinary Medicine. 99, 60-67. 10.1016/j.prevetmed.2011.01.004.

Skuce, P. J., et al., 2016. Livestock Health and Greenhouse Gas Emissions. Climate Exchange, Edinburgh.

Skuce, P. J., et al., 2013. Animal health aspects of adaptation to climate change: beating the heat and parasites in a warming Europe. Animal. 7, 333-345. 10.1017/S175173111300075X.

Smith, R. L., et al., 2014. Economic risk analysis model for bovine viral diarrhea virus biosecurity in cow-calf herds. Preventive Veterinary Medicine. 113, 492-503. 10.1016/j.prevetmed.2013.11.013.

Soussana, J.-F., et al., 2013. Managing grassland systems in a changing climate: the search for practical solutions. In Michalk, D.L. et al. (Eds), 2013. Revitalising Grasslands to Sustain our Communities: Proceedings, 22nd International Grassland Congress, 15-19 September 2013, Sydney, Australia. pp.10-27

Stainforth, D. A., et al., 2005. Uncertainty in predictions of the climate response to rising levels of greenhouse gases. Nature. 433, 403-406. 10.1038/nature03301.

Sterk, B., et al., 2011. How, when, and for what reasons does land use modelling contribute to societal problem solving? Environmental Modelling \& Software. 26, 310-316. 10.1016/j.envsoft.2010.06.004.

Stock, K., et al., 2013. Standardization of health data-ICAR guidelines including health key. In Egger-Danner, C. Et al. (Eds), 2013. ICAR Technical Series No. 17: Challenges and Benefits of Health Data Recording in the Context of Food Chain Quality, Management and Breeding. 75-81.

Stott, A., et al., 2012. Interactions between profit and welfare on extensive sheep farms. Animal Welfare. 21, 57-64.

Stott, A. W., et al., 2010. Reducing greenhouse gas emissions through better animal health. Rural Policy Centre, Policy Briefing. RPC PB 2010/01. Edinburgh: SRUC. 
Szmaragd, C., et al., 2009. A Modeling Framework to Describe the Transmission of Bluetongue Virus within and between Farms in Great Britain. PLoS ONE. 4, e7741. 10.1371/journal.pone.0007741.

Thompson, V., et al., 2014. The development of a dynamic, mechanistic, thermal balance model for Bos indicus and Bos taurus. The Journal of Agricultural Science. 152, 464-482. 10.1017/S002185961300049X.

Tilman, D., Clark, M., 2014. Global diets link environmental sustainability and human health. Nature. 515, 518-522. 10.1038/nature13959.

Toma, L., et al., 2013. Determinants of biosecurity behaviour of British cattle and sheep farmers-A behavioural economics analysis. Preventive Veterinary Medicine. 108, 321-333. 10.1016/j.prevetmed.2012.11.009.

Vagenas, D., et al., 2007. A model to account for the consequences of host nutrition on the outcome of gastrointestinal parasitism in sheep: model evaluation. Parasitology. 134, 12791289. 10.1017/S0031182007002624.

Van Paassen, A., et al., 2007. Can computer models stimulate learning about sustainable land use? Experience with LUPAS in the humid (sub-)tropics of Asia. Agricultural Systems. 94, 874-887. 10.1016/j.agsy.2006.11.012.

Vanderhaeghen, W., et al., 2014. Invited review: Effect, persistence, and virulence of coagulase-negative <em $>$ Staphylococcus $</$ em $>$ species associated with ruminant udder health. Journal of Dairy Science. 97, 5275-5293. 10.3168/jds.2013-7775.

Vanlierde, A., et al., 2015. Hot topic: Innovative lactation-stage-dependent prediction of methane emissions from milk mid-infrared spectra. Journal of Dairy Science. 98, 5740-5747. 10.3168/jds.2014-8436.

Velde, F. V., et al., 2015. Diagnosis before treatment: Identifying dairy farmers' determinants for the adoption of sustainable practices in gastrointestinal nematode control. Veterinary Parasitology. 212, 308-317. 10.1016/j.vetpar.2015.07.013.

Vitali, A., et al., 2015. The effect of heat waves on dairy cow mortality. Journal of Dairy Science. 98, 4572-4579. 10.3168/jds.2015-9331. 
Voinov, A., Bousquet, F., 2010. Modelling with stakeholders. Environmental Modelling \& Software. 25, 1268-1281. 10.1016/j.envsoft.2010.03.007.

Voinov, A., et al., 2016. Modelling with stakeholders-next generation. Environmental Modelling \& Software. 77, 196-220. 10.1016/j.envsoft.2015.11.016.

Von Lampe, M., et al., 2014. Why do global long-term scenarios for agriculture differ? An overview of the AgMIP Global Economic Model Intercomparison. Agricultural Economics. 45, 3-20. 10.1111/agec.12086.

Wall, E., et al., 2010. Developing breeding schemes to assist mitigation of greenhouse gas emissions. Animal. 4, 366-376. 10.1017/S175173110999070X.

Ward, M. P., Lewis, F. I., 2013. Bayesian graphical modelling: Applications in veterinary epidemiology. Preventive Veterinary Medicine. 110, 1-3. 10.1016/j.prevetmed.2013.02.007.

Wauters, E., Rojo-Gimeno, C., 2014. Socio-psychological veterinary epidemiology. A new discipline for an old problem. Society for Veterinary Epidemiology and Preventive Medicine (SVEPM) Conference, 26-28 March 2014, Dublin, Ireland.

Weindl, I., et al., 2015. Livestock in a changing climate: production system transitions as an adaptation strategy for agriculture. Environmental Research Letters. 10, 094021. 10.1088/1748-9326/10/9/094021.

Wieczorek, J., et al., 2012. Darwin Core: An evolving community-developed biodiversity data standard. PloS One. 7, e29715. 10.1371/journal.pone.0029715.

Wilkinson, K., et al., 2011. Infectious diseases of animals and plants: An interdisciplinary approach. Philosophical Transactions of the Royal Society of London B: Biological Sciences. 366, 1933-1942. 10.1098/rstb.2010.0415.

Williams, A., et al., 2013. The benefits of improving cattle health on environmental impacts and enhancing sustainability. Sustainable Intensification: The Pathway to Low Carbon Farming, 25-27 September 2013, Edinburgh, UK.

Wilson, A. J., et al., 2013. Use of a Bayesian network model to identify factors associated with the presence of the tick Ornithodoros erraticus on pig farms in southern Portugal. Preventive Veterinary Medicine. 110, 45-53. 10.1016/j.prevetmed.2013.02.006. 
Wreford, A., et al., 2015. Estimating the costs and benefits of adapting agriculture to climate change. EuroChoices. 14, 16-23. 10.1111/1746-692X.12086. 